\title{
LA CARTA DE POBLACIÓ DELS SARRAÏNS DE LA VALL D'AIORA (1328)*
}

\author{
Per \\ MARIA TERESA FERRER I MALLOL
}

La vall d'Aiora havia estat una de les comarques en litigi entre la Corona catalanoaragonesa i Castella, ja que es trobava dins el límit de la reconquesta d'ambdós estats. Jaume I ocupà una part de la vall el 1244, però la retornà a Castella en compliment del tractat d'Almirra del mateix any (1).

Més endavant, però, Pere el Gran aconseguí pel tractat de Campillo, de 1281. que Alfons el Savi li restituís la vall d'Aiora, en un moment politicament favorable a la Corona catalano-aragonesa, quan tenia a les seves mans els infants de la Cerda, hereus legitims del tron castellà, que havien estat preterits en benefici del secundogènit d'Alfons $X$, I'infant Sanç de Castella (2).

Des de llavors, la vall quedà incorporada a la Corona catalano-aragonesa. La formaven les viles, els castells i llocs d'Aiora, de Teresa de Cofrents, Cofrents, Xarafull, Xalans, Palaciolos i Zarra. Era poblada per una minoria cristiana, establerta a redós dels castelis, especialment a Aiora, i una majoria d'habitants sarrains.

El 16 de gener de 1296 Jaume Il cedí la vall, amb caràcter vitalici, al seu conseller, Bernat de Sarrià, una de les personalitats més rellevants de la seva cort, que li havia prestat grans serveis, tant en l'exèrcit il'armada com en la diplomàcia. Jaume II li concedi totes les rendes que la Corona rebia a la vall, amb l'obligació, però, d'esmerçar-les en la guarda, reedificació, reparació i millora dels castells i en la repoblació de la vall. Els seus hereus haurien de restituir la vall a la Corona (3).

\footnotetext{
1*) Aquest article forma part del conjunt o'estudis realitzats dins del Projecte d'investigació uRelacions entre cristians i sarrains als estats de la Corona catalano-aragonesa en el segle XIV", programa "España y el Islam en la Edad Media", finançat per la Comissió Assessora d'Investigació Científica i Tècnica durant els anys 1982-1984.

(1) JAUME I, Crònica o Llibre dels feits, ed, a cura de F. SOLDEVILA, Les quatre grans croniques, Barcelona, 1971, capltols 241-349, pags. 130-132. J. ZURITA, Anales de la Corona de Aragón, ed a cura de A. CANELLAS LOPEZ, Ilib. III, cap. XLIV, vol. 1, pàgs. 556-558. Sobre la historia de la vall d'Aiora, cf. E. MARTINEZ AZORIN, Historia de la ilustre villa de Ayora, València, 1939, i B. SANZ DIAZ, El valle de Ayora, València, 1982.
}

(2) J. ZURITA, Anales, llib. IV, cap. XI, vol. 2, pàg. 39.

(3) ACA, C, reg. 194, ff. 186v-187r (1296, gener 16). 
Bernat de Sarrià morí vell, de manera que la vall d'Aiora romangué a les seves mans més de, trenta anys. Durant aquest temps, concedi als sarraïns residents a la vall diverses cartes d'establiment i de població, en les quals fixà els impostos que li havien de pagar cada any. Cal suposar que Bernat de Sarrià intentava d'esprémer els sarraïns tant com podia des del punt de vista fiscal i que les queixes d'aquests vassalls i l'ús de llur arma suprema, que era marxar a una altra banda, I'obligaren a anar modificant la carta de poblament, de manera que les condicions económiques fossin més tolerables per als moros.

Sembla que la darrera d'aquestes modificacions és la que publiquem, que fou sancionada pel rei Alfons el Benigne, el 3 d'agost de 1328, ja que la cessió de la vali a Bernat de Sarrià era només temporal i la Corona n'era la propietària.

Abans de la concessió hi havia hagut un cert enrenou a la vall; els moros asseguraven que no podien pagar ni les rendes ni els drets que Bernat de Sarrià havia fixat anteriorment $\mathrm{i}$ havien amenaçat d'abandonar la vall. Alguns en marxaren efectivament i, a més, recorregueren al rei.

El monarca no desitjava que la vall es despoblés, ja que era previsible que tornés aviat a la Corona; per això ordenà a Joan Escrivà, batlle general de València, que fes tornar a la vall els sarrains que n'havien marxat i tranquil. litzés els qui s'hi havien quedat, a fi d'assegurar que continués poblada.

Joan Escrivà anà personalment a la vall d'Aiora i també Enric de Quintavall, conseller del rei, els quals actuaren de mitjancers entre les aljames i Bernat de Sarrià, fins que aquest consentí a derogar la carta de població, els privilegis d'arrendament i d'altres contractes concertats amb els sarraïns de la vall, anteriorment, i acceptà la carta de població que li proposaren els sarrainns per escrit.

A la introducció, Bernat de Sarrià exposà breument els fets que havien portat a la redacció d'una nova carta de població, és a dir, els que acabem de comentar, i les circumstàncies que li havien aconsellat d'acceptar-ho, de l'una banda, els bons serveis que li havien prestat els sarrains anteriorment, de l'altra, la situació fronterera de la vall, que causava molèsties i que, per tant, obligava a concedir més llibertats i franquícies als que hi residien i, finalment, una darrera raó, sens dubte la més important, que era la necessitat de mantenir i d'incrementar la població de la vall, per tal de no perjudicar la Corona, que n'era la propietària (4). Podem suposar, sense gaire risc d'equivocar-nos, que tant Joan Escrivà com Enric de Quintavall degueren recordarho a Bernat de Sarrià i li degueren fer present l'obligació que tenia d'evitar que, després de la seva mort, la vall revertís a la Corona despoblada i empobrida.

Cal dir, però, que el malestar que es produïa entre els sarraïns de la vall no és atribuible només a una pressió fiscal excessiva de Bernat de Sarrià; hi havia també dissensions internes i descontentament contra l'actuació dels cadis i dels alamins, que eren acusats d'haver aprofitat Ilurs oficis per a perjudicar llurs correligionaris; els descontents arribaren a enviar missatgers al rei, que es trobava a Montalbán, pel juliol del mateix any 1328, i aconseguiren que el monarca encomanés al batlle general de València, Joan Escrivà, la investigació del cas, el càstig dels abusos i la destitució dels responsables, si es demostrava que eren culpables(5).

El primer terc del segle XIV no havia estat gaire afortunat per als sarrainns de la vall d'Aiora. Les freqüents alarmes per guerres o situacions pre-bèl.liques amb Granada comportaven nombroses molèsties per als sarraïns. El 1308, per exemple, hom

(4) Cf. l'Apèndix documental.

(5) ACA, C. reg. 431, ff. 165v-166r (1328, juliol, 24). 
temia un atac de Granada i, per aquest motiu, els castells d'Aiora, de Teresa, Xarafull, Xalans i Cofrents foren establerts amb tropes, a fi que es poguessin defensar, si eren atacats; a més, per indicació reial i tal com hom solia fer en aquests casos, Pero Miquel d'Alcoaus demanà rehenes als moros de la vall per tal d'assegurar llur lleiaitat. Els moros lliuraren llurs fills, però protestaren per aquesta mesura discriminatòria que, pel que sembla, els era aplicada per primera vegada. Asseguraren que en èpoques precedents, en períodes de guerra amb Castella o amb Granada, sempre havien contribuit lleialment en serveis de vigilància, com talaies, atalladors etc. i que Bernat de Sarrià ni tan sols no els havia posat alcaids als castells, perquè es fiava d'ells $(6)$.

Més endavant hi hagué tensions amb les poblacions veïnes de Castella, com les que es registraren entre Aiora i Almansa per quëstions de límits entre 1306 i 1308(7). Aquesta mena de plets fronterers donaven peu de vegades a incursions armades en el territori veí per prendre penyores, fer tales etc, com la que realitzà Sancho Jiménez de Lanclares, lloctinent de don Juan Manuel, el mes de juny de 1311 a la vall d'Aiora. L'escamot invasor talà l'horta, matà tres moros, en ferí vint i se n'endugué catorze, a més de cinc-centes vaques, cent eugues i mules i 7.512 caps de bestiar menut. Don Juan Manuel s'excusà pels danys causats, però el 1313 encara no havia indemnitzat els homes de la vall que, de resultes de l'atac, havien quedat en la pobresa(8).

Cap al 1316, hi hagué nous enfrontaments entre els veïns de Chinchilla i els d'Aiora per motius que ignorem. Els d'Aiora es queixaren de la captura de veïns seus, que $s^{\prime}$ havien hagut de rescatar $i$, com que els castellans no s'afanyaven a indemnitzarlos, ho féu Jaume II, descomptant-ho de l'aixovar de la seva filla, que encara restava per pagar, en part, a don Juan Manuel (9).

A les pèrdues ocasionades per les incursions frontereres, cal afegir-hi les derivades de secades i de males anyades agrícoles, amb la seqüela de carestia, com s'esdevingué l'any 1314, en què calgué aprovisionar la vall des d'altres llocs (10).

El 1317, quan encara no s'havien recuperat d'aquests cops, els moros de la vall hagueren de pagar al rei una multa col.lectiva de 8.000 sous perquè havien acollit i amagat una sarraïna captiva, que havia fugit al seu amo, Berenguer de Fluvià, de Xàtiva. El procurador de Bernat de Sarrià a la vall, Ramon Muntaner, el famós cronista, fou l'encarregat de negociar la remissió col. lectiva i d'efectuar el pagament de la composició $(11)$.

\section{La carta de poblament}

La carta de poblament es presenta com un pacte bilateral entre Bernat de Sarrià i els síndics de les aljames de la vall, que la signaren a València el 23 de juny de 1328. Els sindics sarraïns signants foren Hamet Abenjucef el Ballestero i Caad Matrabel. El primer era síndic de l'aljama de Cofrents i el segon de l'aljama de Xarafull; ambdós

(6) ACA, C, cr. Jaume H, núms. 3552. i 3554 (1308, juny, 12 i 13 ).

17) A. GIMÉNEZ SOLER, Don Juan Manuel, Saragossa, 1932, docs. 146 i 178, pàgs. 333 i 353 . Cf. també ACA, C, reg. 237 , f. 70 r (1308, abril, 22)

(8) ACA, C, reg. 239, f. 108r-vi 109r (1311, juliol, 4) if. 110v (1311, juliol, 27), reg. 240, ff. 6v (1312, maig, 3) i 150v-151r $\{1313$, febrer, 5$\}$.

19) ACA, C, reg. 243, ff, 154r-v (1316, agost, 22) i 191v-192r (1316, novembre, 30). Sobre el casament de la infanta cf. A. GIMÉNEZ SOLER, Don Juan Manuel, pags. 32 i 49.

(10) ACA, C, reg. 241, f. $117 \mathrm{~V}(1314$, febrer, 6).

111) ACA, C, reg. 215, ff. 190v-191r (1317, novembre, 25). Cf. més detalls sobre aquest incident a M. T. FERRERI MALLOL, La redempció de captius a la Corona catalano-aragonesa (segle XIV), en curs de publicació a l' anuario de Estudios Medievales. .18 , text corresponent a les notes $26-25$. 
representaven al mateix temps, com a procuradors substituts, uns altres síndics, que devien haver intervingut també en les negociacions, però que no havien pogut desplaçar-se a València per a la signatura de la carta: Alí Abnalbayda, síndic de Cofrents - com el mateix Hamet - Alí Abencacim, síndic de Xarafull -com Çaad Matrabel_-, Çaad Almorayem, Hamet Abenacap, síndics de Xalans, Hamet Tarraboni i Çaad Abençale, síndics de Teresa i de Palaciolos, i Alí Abenaxa i d'altres que no són anomenats, síndics de l'aljama de Zarra. Cal notar que no és esmentada cap aljama del lloc d'Aiora, que devia ésser exclusivament, o gairebé, vila cristiana.

\section{Els impostos}

Naturalment, els punts de més interès de la carta són els relatius als impostos, puix que era aquest el motiu de les diferències entre Bernat de Sarrià i les aljames.

Impostos generals. Entre aquests impostos cal esmentar en primer lloc l'alfarda, equivalent a la peita o quèstia dels cristians. L'alfarda era un impost comunitari, és a dir, gravava el conjunt d'una comunitat sarraïna, encara que, com veurem, no afectava tothom. Consistia en una quantitat fixa anual, que després la mateixa comunitat, els vells o els altres oficials de l'aljama, repartia entre els seus membres, però només entre els qui tenien terres, suposem que segons llurs possibilitats econòmiques.

La carta de població de la vall d'Aiora contribueix, doncs, a aclarir la naturalesa d'aquest impost, que ha estar molt discutit. S'ha dit que, en alguns casos, podia ésser un impost sobre l'ús de l'aigua a les terres de regadiu, però que en molts d'altres era assimilable, de manera indubtable, a la peita (12). Ignorem els origens de l'impost, però sembla clar que té un cert lligam amb la propietat de la terra, ja que els qui no en tenien n'estaven exempts, almenys a Aiora i també a Alacant, on els eixàrics tampoc no havien de pagar-la, precisament perquè no tenien terres pròpies (13).

La qualitat de propietari havia de coincidir amb la de resident a la població, altrament no hauria estat possible la defraudació imaginada per alguns sarraïns d'Elx que, tenint terres a Elx, es domiciliaven en terres de barons pròximes per tal de no pagar alfarda a Elx, on no residien, ni tampoc al lloc on s'estaven perquè no hi tenien terres (14).

Com veurem, l'alfarda es complementava amb l'impost del besant, que afectava aquells qui no tenien terra (15).

La quantitat assignada per la carta a la vall d'Aiora, en concepte d'alfarda, fou de 2.000 sous "solament»; suposem que la inclusió del mot "solament" deu significar que els sarrains havien aconseguit una rebaixa en aquest capítol (16). Pensem que I'aljama d'Asp pagava, ella tota sola, 2.000 sous anuals d'alfarda el 1315 (17).

L'alfatrà era un altre dels impostos generals que apareix a la nostra carta de població. Era un impost personal, una mena de capitació que pagava tothom, homes i dones, petits i grans. Consistia en un almud d'ordi cada any $(18)$. Hem trobat també aquest

\footnotetext{
(12) R. I. BURNS, Medieval Colonialism. Postcrusade Exploitation of /slamic Valencia, Princeton, 1976, pags. 127-137.

113) ACA, C, reg. 228, f. 99 r (1326, maig, 8)

114) ACA, C, reg. 244, f. 150r (1318, març, 10). Cf. sobre aquest tema M. T. FERRER I MALLOL, Els sarräns de la Corona catalano-aragonesa. Segregació i limitació de libertats, en curs de publicació, cap. 7 , text corresponent a la nota 60.

(15) Apèndix documental, cap. [7].

(16) Ibidem, cap. [3].

(17) Colección de documentos inéditos del Archivo de la Corona de Aragón, val. XXXIX, a cura de M. DE BOFARULL Y de SARTORIO, Barcelona, $1871, \mathrm{pag} .125$.

(18) Apèndix documental, cap. [4].
} 
impost a les comarques d'Alacant i d'Oriola i Elx. Quan s'han conservat les xifres de rendiment de l'alfatrà, podem conèixer exactament la població sarrainna d'un lloc.

L'impost de gallines afectava tothom també, però amb caràcter familiar, és a dir, es pagava un parell de gallines per casat o el seu equivalent de 16 diners. Cal assenvalar que en aquest capitol, els moros de la vall d'Aiora no aconseguiren cap rebaixa notable, ja que el 1319 la gallina d'aquest impost era valorada a Crevillent i 'a Elx a 6 diners (un parell serien, doncs, 12 diners). A Asp I'equivalència era igual que a la vall d'Aiora, de 8 diners, mentre que a Elda i Novelda era superior, de 10 diners la gallina, bé que tots aquests llocs havien de lliurar només una gallina per casa (19). Si per cas, el fet que l'equivalència del parell de gallines fos a la vall més aviat alt resultava compensat per l'obligació del senyor i dels seus oficials de pagar al mateix preu totes les gallines que prenguessin per a llur servei (20).

El besant era un impost que afectava només els sarraïns que no tenien heretats, tal com ja ho hem dit. Cada família pagava un besant. La carta especifica l'equivalencia del besant: 3 sous i 6 diners per besant i fa constar també que aquests sarraïns no es trobaven pas exempts de l'alfatrà ni del dret de gallines ni del de bestiar i colmenes ni dels serveis. Com que no es fa menció de l'alfarda, cal concloure que n'eren exempts (21).

El monedatge és citat també entre els impostos que havien de pagar els sarraïns (22). Com que es tractava, però, d'un impost general de tota la Corona catalano-aragonesa, que afectave cristians i sarrains, no era a les mans de Bernat de Sarrià de fer-hi modificacions i, per tant, no n'és esmentada la taxa.

Igualment hi ha una referència a lleudes i peatges, que afectaven igualment cristians i sarrains, i en els quals la carta no introdueix cap modificació (22).

impostos agraris. Les terres regades havien de pagar, segons la carta de població, un dret per alfaba, concretament 18 sous anuals pẹ alfaba. Era l'impost anomenat almagram, bé que la carta no esmenta aquest nom (24).

L'alfaba era la unitat fiscal de conreu que tenia en compte l'extensió de la terra, la qualitat, els arbres que hi havia plantats etc. (25).

La carta disposava que el cadi Almateri fes un soguejament de la vall, és a dir, una mena de cadastre, i que en determinés les alfabes. Cadascú hauria de pagar segons les alfabes fixades pel cadi. Cada set anys caldria inspeccionar les alfabes, per tal de posar-les al dia de millores o deterioraments (26).

A més de l'impost de les alfabes, calia pagar un impost complementari, anomenat xerifia, que pujava a 2 sous per alfaba (27). Ignorem la naturalesa exacta d'aquest impost.

Les vinyes tenien un tractament fiscal diferent. Com que el conreu n'era uniforme,

\footnotetext{
(19) ACA, C, reg. 217, f. 168v (1319, agost, 1) i RP, MR, reg. 1721, ff. Tv, 7v i 12v, i reg. 1711, ff. 12v, 16r i $20 \mathrm{r}$.

(20) Apèndix documental, cap. [5]

(21) Ibidem, cap. [7].

(22) Ibidem, cap. [24]

(23) Bidem.

(24) Cf. un resum dels impostos morises, amb un estudi comparatiu entre diferents lloos, a P. GUlCHARD. La conquista milifar y la estructuración política del reino, a Nuestra Historia, 3, València, 1980, pàgs. 75-80.

(25) J. TORRES FONTES, Medidas de superficie $\mathrm{r}$ de valoración en el repartimiento de Murcia, "Murgetanaw, XII (1959), paginas 8-19 de l'extret.

(26) Apèndix documental, cap. [1].

(27) Ibidem, cap. [2].
} 
la taxació de l'impost no es feia per alfabes sinó per tafulles, és a dir, per extensió de terra plantada amb ceps. L'impost pujava a 6 diners per tafulla cada any. Les vinyes plantades de nou tenien una franquícia de cinc anys, per ajudar a l'amortització dels ceps i dels primers temps de vinya jove, en què el rendiment era nul o escàs (28).

Els secans, de rendiment irregular, pagaven impost segons la collita. L'onzè era la quota establerta (29).

Les terres dites dels almatzems, terres lliures o vacants, no concedides a ningú, podien ésser llaurades per qualsevol moro, amb l'obligació de lliurar el terç de la collita (30).

En tots els casos calia donar, a més, al senyor el delme i les primícies de tots els conreus, tant dels que es feien en terres de regadiu (31), com de les vinyes (32), o dels secans (33).

Pel que fa a l'aprofitament dels erms, els sarraïns només tenien lliure la recol. lecció de la grana, perquè ho era per fur atorgat pel rei Jaume, tant per a sarraïns com per a cristians (34). Segons la carta de poblament només els forasters haurien de pagar un impost que no és especificat (35). En canvi, Bernat de Sarrià retenia el delme de la caça i de la fusta, el dret de la sal, que ignorem a quan pujava, i l'herbatge, partida important en un lloc on acudien molts caps de bestiar transhumant (36).

impostos sobre el bestiar. En un sistema fiscal com el que dibuixa la carta de població, no hi podia faltar l'impost sobre el bestiar, que era a tot arreu un complement de l'economia agrícola i, per tant, matèria imponible. Crida l'atenció el fet que l'impost fa referència només a bestiar menut i únicament fa menció expressa de les cabres i dels cabrits; cada cap havia de pagar un diner (37). El bestiar vacum no hi és esmentat en absolut. Podriem deduir-ne que, o bé els moros no poseien aquesta mena de bestiar o bé que no eren subjectes d'impost. Ens inclinem a creure més aviat que es tracta d'aquesta segona hipòtesi i que el bestiar vacum era considerat eina de treball, com les mules i els ases, que tampoc no apareixen en aquest capítol, però que són esmentats en un altre indret, quan es fa referència a les prestacions exigibles als sarrains $(38)$.

El mateix capítol recull també l'impost que gravava les colmenes o ruscs d'abelles. que era també d'ún diner per rusc. La carta puntualitza que, tant el bestiar com els ruscs, serien comptats el mes d'abril per tal de fixar-ne l'impost a pagar per cadascú (39).

La carta s'ocupa tambë de la manera de fer efectius tots aquests impostos, que

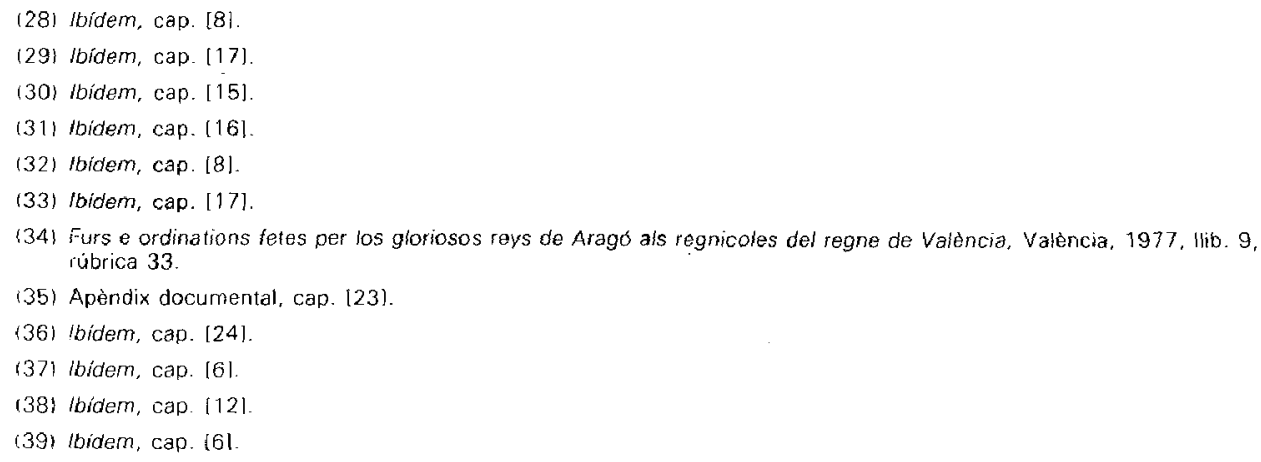


es dividien en dues tandes a pagar en dos terminis anuals: I'un era tot el mes de gener i l'altre tot el mes d'agost (40).

Monopolis. Molins, forns, banys i tavernes eren propietat del senyor i no mereixen cap més comentari a la carta. Es possible que fossin arrendats o cedits en emfiteusi $\{41\}$.

Serveis o Sofres. És en aquest punt on, potser, es nota.més la liberalitat de la carta de població d'Aiora. Generalment, els sarrains estaven obligats a fer uns determinats dies d'obres per al senyor, a traginar collites, aigua i llenya per al castell, a deixar roba i eines de casa per al senyor o per al seu procurador etc. A la carta de la vall d'Aiora molts d'aquests serveis també hi són considerats, però no n'hi ha cap de gratuitt.

Hi consta que els moros de la vall han de treballar en totes les obres que el senyor faci a la vall, tant les dels castells com les altres, pero a jornal de 8 diners diaris i pagats al comptat, com els obrers forasters que hi treballessin, cosa que fa suposar que prèviament la remuneració d'aquesta mena de feines no havia estat gaire regular (42).

Pel que fa a la prestació de bèsties de transport, tant per a viatges del senyor, com per a fer obres, traginar la part pertocant al senyor de les collites etc. era cosa obligada, però també gratificada necessàriament: 12 diners diaris per cada mula o bèstia major i 8 diners per ase; a més, el senyor havia de pagar la provisió per a la bèstia i per a la persona que la menés. També en aquest cas el pagament havia d'ésser al comptat (43).

La carta no cita més serveis, de manera que cal concloure que aquests n'eren els únics admesos.

Franquícies i privilegis. La carta de població dels sarraïns de la vall d'Aiora conté també alguns privilegis atorgats per Bernat de Sarrià, que poden ésser franquícies de caràcter econòmic o de serveis o bé concessions de tipus judicial o d'altres.

Hi ha, per exemple, la franquícia de treta de blat i d'altres grans collits a la vall cap a uns altres llocs del regne de València. L'única limitació imposada a aquesta llibertat és el dret del senyor de decretar prohibicions de treta per causa de guerres, carestia o d'altres necessitats (44).

Una franquícia de serveis és la dispensa de participació en hosts i cavalcades, llevat de les convocades generalment pel rei o d'aquelles en les quals Bernat de Sarrià anés personalment o que es fessin per afers propis del noble esmentat (45).

La carta s'ocupa també dels afarrassaments a alfarrassaments, és a dir, de l'avaluació a ull dels fruits agrícoles abans d'ésser collits i que servia per a fixar-ne l'impost. Era, per tant, una operació delicada; en depenia que la pressió fiscal estigués repartida de manera justa i equitativa i calia, doncs, que fos feta sense favoritismes ni mala voluntat envers ningú. La carta disposà que es fessin conjuntament per un cristià i

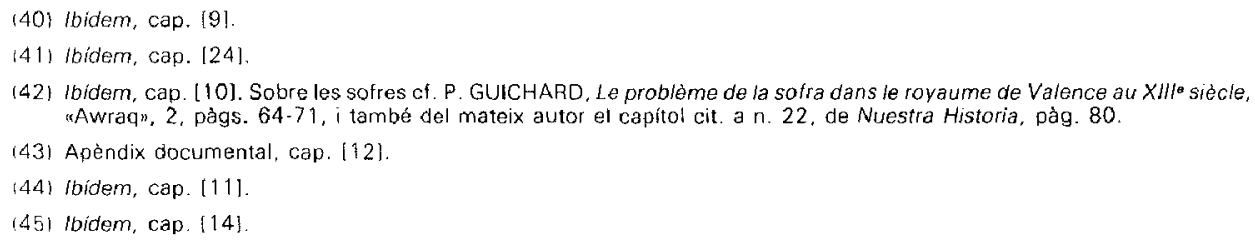


per un sarrai nomenats pel senyor i davant ef procurador i el batlle de la vall. Els sarraïns de cada lloc podrien demanar còpia de I'alfarrassament (46).

Unes altres concessions es refereixen a la transmissió de béns, tant per herència com per compra-venda, que solien tenir moltes limitacions i recàrrecs quan afectaven els membres de la minoria sarraina. A la carta de 1328 la compra-venda de terres entre sarraïns fou declarada lliure; només aniria gravada pel dret de lluisme del senyor (47). La successió de béns per herència quedà totalment lliure i sotmesa a la regulació de la sunna (48). Cal remarcar que en aquests punts la carta és molt generosa perqué, a la major part dels llocs, la compra-venda de béns immobles havia de pagar una cinquena part del preu de venda al senyor (49).

La carta inclou també la salvaguarda de les propietats de les mesquites; la mesquita de cada lloc de la vall podria disposar de tres tafulles de terra de regadiu completament franques, lliures de tot impost (50). És l'única referència en tota la carta als drets religiosos dels sarraïns. No hi ha cap menció de pràctiques conflictives, com la crida de la salà, que havia estat objecte de prohibicions severes (51).

Tampoc no hi ha disposicions sobre l'organització interna de l'aljama: elecció de càrrecs, competències d'aquests càrrecs, etc. Només hi ha concessions referents a l'administració de la justícia, que seria competència del cadi. Les sentències del cadi podrien ésser apel.lades al tribunal de qualsevol altre cadi de llocs reials del regne de València i les penes d'assots haurien d'ésser aplicades segons sunna (52).

Bernat de Sarrià es comprometé solemnement a no exigir més serveis ni impostos dels que havien estat especificats a la carta i, si els exigia, els sarraïns es podrien negar a pagar-los 0 , si els pagaven, seria per propi voler i liberalitat.

Els sarrains, de llur banda, es comprometeren a pagar els impostos i les rendes en els terminis establerts i a millorar i llaurar les terres com a bons llauradors i a comportar-se com a vassalls lleials.

Poc temps després, els mateixos síndics que havien negociat la carta s'encarregaren d'obtenir la confirmació del rei, a fi que els beneficis obtinguts romanguessin garantits pel consentiment de la Corona, a la qual calia esperar que la vall retornaria al cap de poc temps.

Sovint, les cartes de població són com una mena de radiografia d'una comunitat. Si considerem la que comentem des d'aquest punt de vista, hem de concloure que els moros de la vall d'Aiora vivien de l'agricultura, completada amb ramaderia de cabres, pollalla i apicultura i amb productes silvestres i d'aprofitament lliure, com la grana.

No hi és mencionat cap impost sobre activitats artesanals: ni sobre telers de fer estores, ni sobre terrissa, per posar-ne un parell d'exemples, com en altres aljames, de manera que hem de suposar que no hi havia producció artesanal que sobrepassés els límits de la comunitat; la petita artesania, destinada a cobrir les necessitats de la població autòctona, no devia merèixer cap impost especial a causa del seu rendi-

\footnotetext{
446) Jbidem, cap. \{13\}.

1471 lbidem, cap. 181

(48) bidem, cap. [19]

(49) A /'Aldea, per exemple, els sarrains havien de pagar als hospitalers la cinquena part del preu de venda de llurs heretats

P. GUICHARD, La conquista militar, p. 79

(50) Apèndix documental, cap. 120$\}$.

151 M. T. FERRER I MALLOL, Els sarrains de la Corona catalano-aragonesa, cap. 4.

i52) Apèndix documental, cap. 1221
} 
ment econòmic escàs. Si algú s'hi dedicava exclusivament, devia resultar taxat de manera suficient amb l'impost dels qui no tenien heretats, és a dir, amb el besant.

Tampoc l'agricultura no devia ésser excessivament rica. Els moros es preocupaien només d'obtenir franquícia de treta per a llurs excedents de blat i d'altres grans, que devia ésser el conreu més important.

En conjunt, els moros de la vall d'Aiora fan l'efecte d'ésser una comunitat més aviat pobra.

\title{
APÈNDIX DOCUMENTAL 1328, agost, 3. Cariñena
}

\author{
ALFONS EL BENIGNE CONFIRMA LA CARTA DE POBLACIÓ \\ ATORGADA PER BERNAT DE SARRIÀ ALS SARRAINS DE LA VALL D'AIORA \\ EL 23 DE JUNY DE 1328
}

ACA, C, reg. 476, ff. 154 r. -1584 r.

Al marge superior, en lletra del s. XVII: Sarracenos vallis de Ayora.

Nos, Alfonsus, et cetera. Viso quodam publico instrumento per litteras diviso nobis ostenso per procuratores aliamarum sarracenorum locorum vallis dé Ayora, cuius instrumenti tenor noscitur esse talis:

Coneguem tots que com per nós, en Bernat de Sarrià, conseyller del seynor rey, fossen feytes e atorgades moltes e diverses cartes d'establiments e de població e altres privilegis e concessions als sarrahins habitants en la vall de Ayora, la qual nós tenim a violari del senyor rey e per certs ayns aprés nostra vida a e sots certes condicions, segons que en lo privilegi de la donació feyta per l'alt seynor rey en Jacme de bona memòia, pare del seynor rey ara regnant, e lo qual privilegi és ab bolla de plom bollat, és contengut, per les quals cartes e privilegis los dits sarrahins heren cascuns ayns tenguts donar e pagar certs drets e rendes a nós. E com per moltes e diverses rahons los dits sarrahins, segons que denant nós han exposat, no poguessen a les dites rendes e drets, ordenats en los temps passats donar e pagar, complir e dixessen que si gràcia no-Is eren feyta haurian a desemparar la dita vall, com alguns ja ne fossen exits per la dita rahó e per les peytes e altres exaccions que pagavan e per aquesta rahó recorreguessen at seynor rey, e lo dit seynor rey ab carta sua manàs al honrat conseyller seu en Johan Scrivà, batle general del regne de València, que ell degués los dits sarrahins, qui exits heren de la dita vall, fer tornar e aquells qui heren romasos assegurar en tal manera que la dita vall se poblàs, lo dit batle general hanàs personalment a la dita vall e, vista aquella, feés e complís les coses per lo seynor rey manades. E com enaprés, tractant lo dit batlle e.| honrat cavaller n'Errigo de Quintavall, conseyller del dit seynor rey, los síndichs e procuradors de les aljames dels dits sarrahins ab gran ${ }^{b}$ reverència instassen, requerissen e suplicassen a nós que, cassades totes cartes de població, privilegis d'arrendaments o loguers o qualssevol altres contractes feyts entre nós e los sarrahins de la dita vall en los temps passats tro al present dia deguessem a aquells fer novelles cartes e concessions de població e d'establiments, sots certs capítols per ells a nós offerts e donats per scriptura, dels quals menció dejús largament feita és, per tal que la dita vall se reparàs e.s poblàs, nós, dit en Bernat de Sarrià, attenents que en los temps passats havem acostumat fer bé e gràcia e mercè als dits sarrahins, axí com aquells qui han bé servit nós de lur poder, volèn aquells de majors gràcies proseguir e favors, havèn esguart aquells ésser poblats 
en loch de ffrontera, perquè són dignes de majors libertats e franquees, moguts per les dites rahons e desigan encara que la dita vall, la propietat de la qual s'esguarda al senyor rey, prenga creximent, millorament e població, per ço, revocan totes cartes, privilegis e establiments e de loguers e de arrendaments feites en los temps passats tro a aquest dia, novellament atorgam e donam als sarrahins de la dita vall e a Hamet el Balestero, constituït síndich e procurador, ensemps ab Alí Abnalbayda, dels sarrahins de la aljama de Confrontes, e a Çaad Matrabel, síndichc e procurador, ab Alí Abencaçim ensemps, constituit de la aljama dels sarrahins de Xarafull e encara a aquests, axi com a procuradors substituits de Çaad Almorayem e Hamet Abenacap, sarrahins, síndichs e procuradors dels sarrahins de la aljama de Xalans e axí com a procuradors substituïts de Hamet Tarraboni, síndich e procurador, ab Caadd Abençale ensemps, dels sarrahins dels lochs de Theresa e de Palaciolos e axi encara com a procuradors ${ }^{e}$ substituïts de Alí Abenaxa, síndich e procurador ab altres ensemps de la aljama dels sarrahins del loch de Açarra, los quals dits Hamet Abenjuceff e Çaad Matrabel $f^{f}$, presents, en nom lur e dels sarrahins e aljames de la dita vall reebents, e als quals de les aljames damunt dites e de lurs síndichs ab cartes públiques feites per lo notari davall scrit poder és atorgat e donat de reebre de nós les coses dejús scrites e fermar e atorgar aquelles per les dites aljames, les terres de regadiu e sequà e vynes e arbres e plantes que són en la dita vall, les quals los dits sarrahins han acostumat laurar, tenir e possehir en los temps passats e d'aquí enant poran laurar, sens prejudici emperò del dret d'altre, assí emperò que Is dits sarrahins e lurs successors en per ${ }^{9}$ tots temps d'aquí enant, tant com nós e los nostres la dita vall tindrem, donen e sien tenguts a nós donar los drets dejús escrits e especifficats per les terres e vynes, arbres e plantes de la dita vall e nenguns altres rendes, peites, servhiis o dons no sian tenguts donar ni a donar aquellas puschan aquells ni.ls lurs costrèyner ni forçar, si donchs de lur liberalitat no era.

[1] Primerament, que los sarrahins qui són e seran en la dita vall donen e sien tenguts donar a nós e als nostres cascuns ayns per cascuna alhaba de terra d'aquelles que són o seran en la dita vall deehuyt sous ${ }^{h} e d^{\prime}$ aquelles alhabbes que en la dita vall atrobades seran per l'alcadi Almateri, per lo qual la dita vall sia soguejada e volem que sien feites per aquell les alhabbes e lo qual ans que y començ jur segons sa ley que en fer les dites alhabbes bé e lealment se haurà e volem que de set en set anys les alhabbes sien regonegudes e soguejades

[2] Item, que.Is dits sarrahins donen e sien tenguts donar per cascuna alhabba per lo dret de la xerifia dos sous.

[3] Ítem, que cascuns ayns los sarrahins de la dita vall donen a nós e als nostres per alfarda o peyta II mil sous tan solament.

[4] Ítem, que cascun sarrahí sia tengut donar per alfatrà per cascun cap de sarrahí o sarrahina, axí poc com gran, I almut d'ordi.

[5] İtem, que.Is sarrahins habitants en la dita vall donen per cascun casat I pareyll de galines tan solament o per preu d'aquelles XVI diners. Emperò si nós serem en la dita vall o nostres domèstichs puscham pendre e haver de les galines de la dita vall les que haurem necessàries a provisió nostra e lur, donan XVI diners per cascun pareyll de galines.

[6] Ítem, que tots los sarrahins habitants e habitadors en la dita vall donen e sien tenguts donar cascun aný per cascuna cabra o per cascun cabrit e cascuna cabeça de bestiar menut que hauran un diner, e per cascuna colmena que hauran un diner, lo qual bestiar e colmenes sien comptats en lo mes de abril e, segons ço que-Is serà atrobat, adonchs paguen lo dit dret. 
[7] Item, que.Is sarrahins habitants e habitadors en la dita vall, los quals no hauran heretat, donen a nós e als nostres cascuns ayns un besant per casat, e per io dit besant paguen III sous VI diners, e oltra açò donen lo dret de la alfatrà e les galines e lo dret del bestiar e de les colmenes e encara façan los serviis per si e ab lurs bèsties que.Is altres sarrahins de la dita vall deuen fer

[8] Ítem, que de totes les vynes plantades e d'aquelles que d'aquí enant se plantaran donen e sien tenguts donar a nós e als nostres $V I$ diners per cascuna tafulla e delme e primícia e nós de gràcia atorgam e volem que de les vynes que s plantaran d'aquí enant en la dita vall per $V$ ayns contínuament següents aprés que plantades seran no donen alguna cosa, ans las hajan franques, mas passats los dits $V$ ayns donen los dits VI diners per tafula, segons que dit és, e delme e primícia.

[9] İtem, que.Is sarrahins habitants e habitadors de la dita vall los drets e rendes que hauran a donar per les alhabbas e per l'alfarda e per les colmenes, bestiars e vynes e altres drets donen e sien tenguts ${ }^{k}$ pagar a nós cascuns ayns la meytat per tot lo mes d'agost e l'altra meytat per tot lo mes de giner següents.

[10] Ítem, que /s dits sarrahinis habitants e habitadors en la dita vall obren e sien tẹnguts obrar en totes obres nostres que nós farem fer en la dita vall, assí en los castells com en altres lochs de la vall, nós donan a aquells VIII diners per jornal, los quals volem que.Is sien pagats encontinent cascun dia, segons que als altres obrers estranys lur loguer serà donat e pagat.

[11] İtem, volem e atorgam als sarrahins de la dita vall qu'éls lo forment e als altres blats que hauran e coylliran en la dita vall pusquen traher de la dita vall e portar e fer portar a quals parts se volran dins lo regne de València, franchament e quítia e sens alguna exacció o reençó. Retenim, emperò, que si a nós o als nostres serà ben vist que per rahon de guerra, que fos o esperàs ésser, o per caristia e evident necessitat a bon estament de la vall, o puscam vedar e fer inhibició, axí emperò que per diners o reençó a alcú gràcia no sia per nós feyta que lo $y$ poguessen treher e que als altres fos vedat.

[12] Retenim, emperò, a nós e àls nostres que tota hora que nós o nostre procurador tansolament haurem mester bèsties alcunes de la dita vall per menar per camí e per fer obres e per coyllir les rendes e drets de la dita vall puscam pendre de les bèsties de la dita vall les que haurem necessàries donan a cascuna bèstia mular o bèstia major per son loguer XII diners per jornal e per bèstia asinina VIII diners e provisió a la dita bèstia e al hom qui la menarà, lo qual loguer volem que sie pagat encontinent que hauran feit lur servhii."

[13] Ítem, volem e atorgam que Is affarraçaments que s faran en la dita vall sien feyts per tots temps per I christian $e^{n}$ I sarrahín, los quals hi sien elets e posats per nós e present lo procurador o batlle nostre de la dita vall e los aferraçadós de l'afarraçament juren que bé e lealment s'auran en lo dit affarraçament fahedor, a profit nostre e dels sarrahins de la vall a lur bon enteniment, gitat tot oy e mala volentat e favor; e feyt lo dit affarraçament, que encontinent ne sie donat translat als sarrahins de cascun loch, si haver-lo.n volran, per ço que frau no hi sia feyta e tota suspición ne sie remoguda.

[14] Ítem, volem e atorgam que els sarrahins de la dita vall no sien tenguts hanar per nós en host ni en cavalcada, si donchs lo senyor rey aquella generalment al regne no demanava, o nós en aquella ost o cavalcada personalment no hanàvem o per nostres feyts propris verdaderament aquells no havíem mester, en les quals coses aquells sien tenguts nós seguir en host e en cavalcada. 
[15] Item, volem e atorgam als sarrahins de la dita vall que cascun pusque laurar o fer laurar de les terres dels almatçems, donan lo terç deis esplets que en les dites terres dels almatçems seran o d'aquèn pervendran.

[16] İtem, volem e atorgam que els sarrahins de la dita vall de les terres del regadiu de la dita vall, oltra ço que donar deuen e sien tenguts donar e pagar lo delma e la primicia.

[17] Item, volem e atorgam que els sarrahins de la dita vall dels esplets que hauran de les terres dels sechans sien tenguts donar delme e primícia e la onçena tansolament a nós dels dits esplets.

[18] Ítem, volem e atorgam als dits sarrahins habitants e habitadors en la dita vall que pusquen vendre les terres que han e hauran en la dita vall a altres sarrahins, donan a nós e als nostres loysme del preu per lo qual les dites terres seran venudes.

[19] Item, atorgam e volem que cascuns sarrahins habitants e habitadors en la dita vall pusquen sos béns donar e leixar als seus e ells succeir los béns de lurs parents e altres sarrahins, segons que per çuna se deu fer.

[20] Ítem, volem e atorgam que a cascuna meçquita de cascun loch de la vall sien jaquides tres taffulles de terra del regadiu, de les quals dret alcú no.y sia donat a nós ni als nostres.

[21] item, volem e atorgam que los açots que seran feyts per punir e castigar los malfeitors sarrahins sien feits segons que per çuna se deuen fer e los sarrahins sien açotats segons que per çuna se deuen donar.

[22] I Item, volem e atorgam que los sarrahins habitants en la dita vall e habitadors per-los maleficis que faran, de què seran acusats o contra ells enantat, sien sentenciats per lo nostre alcadi emperò, si de la sentència del dit alcadi per agreviats se tendran, se pusquen appellar a qualsevol alcadi del regne de València dels lochs propris del senyor rey e nós de necessitats los siam tenguts reebre la appellació e assignar dels alcadis del senyor rey dels lochs propris del senyor rey del regne de València.

[23] Item, volem que de la grana que-Is sarrahins de la vall coylliran façen segons que. Is christians de la dita vall deuen fer e segons que en lo privilegi del seynor rey en Jacme és contengut. Quant als estrayns retenim que.n hajam lo dret que donar deuen.

[24] Retenim, emperò, a nós e als nostres en la dita vall, molins, forns, bayns, peatges, leudes, tavernes, calònies, monedatge e lo delme de la caça e de la fusta e lo dret de la sal e el herbatge e les terres nostres pròpries que aqui havem e tots altres drets, los quals nós e los nostres havem acostumat reebre, oltra los drets que.s paguen periles terres e oltra la peyta e los drets desús especificats.

Exí, sots res dites condicions e retenguts a nós e als nostres los drets damunt dits, volem e atorgam que.Is sarrahins que en la dita vall són o seran d'aquí enant pusquen habitar e estar aquí salvament e segura e que a donar als altres drets o serviis, préstecs ne a fer per nós alcunes obligacions no sien tenguts ne obligats ni nós per les dites coses a fer o complir, donan o pagan los drets desús espressats a nós o a qui nós ${ }^{p}$ volrem e entram entre mans o obligàsem per aquelles rendes, aquells no puscham costrèyner ni forçar; e ells sien tenguts la dita vall e les terres, vynes e plantes que alí són ben laurar, conrear e guardar, segons que bons lauradors deuen e són tenguts fer, mylloran tota hora e en res no pigoran, prometents e a bona fe covinents a vós, dits Hamet el Balastero e Çaad Matrabel, síndichs e procuradors de 
les aljames de la dita vall, presents, e en nom vostre e dels sarrahins de les aljames. de la dita vall e axi com a síndichs lurs reebents e al notari dejús scrit, axí com a pública persona de nós ensemps ab vós estipulant•e reebent en nom dels dits sarrahins e aljames que són absents e d'aquells a qui pertayn o pertàyner pot e deu, que nós totes les dites coses d'aquí enant servarem e contra aquelles no vendrem ne farem venir en aalcuna cosa e que vós e los altres sarrahins, pagan a nós los dits drets, segons que desús són especificats e expressats, ni vostres béns ni d'aquells no forçarem ne forçar o destrèyner puscham a donar e pagar o prestar alcuna cosa ni de vós haver per alfarda, peyta, cena ni altres coses subsidis o ajudes, ans si d'aquesta rahó per nós a vós alcuna cosa manada o demanada era ésser per vós feita o als nostres procuradors, batles, alcadis o aljames o altres oficials de la dita vall letres o manaments eren trameses o feites, aquelles letres o manaments no dejen observar ni tenir e, si lo contrari era per aquells feit, vós ni algun de vós no siats tengut servar ni obeyr manaments alcuns o forçes o destrets que per la dita rahó feites vós fossen, si no aytant com de vostra pròpria liberalitat e benivolència fer volríets. Manants per la present carta nostra a tots e sengles officials nostres de la dita vall, presents e qui per temps seran, que les coses en la present carta contengudes fermes e segures hajen e aquelles observen e observar façen e tinguen sens alcun interrumpiment e contra les dites coses no vinguen ne alcun venir façen o lexen per alcuna manera, si de la nostra gràcia o mercè confien; e per ço que les dites coses major fermetat hajen juram per Déu e los sants IIll Evangelis de Déu Seynor, de nostres mans tocats, les dites coses fermes e segures haver e observar e contra aquelles no venir per alcuna manerar si Déus nos hajut e los sants quatre Evangelis.

E nós, dits Hamet el Balestero e Çaad Matrabel, síndichs e procuradors constituïts de les aljames de la dita vall e de lurs síndichs e procuradors, en nom nostre e de nostres principals reebents de vós, noble en Bernat de Sarrià, la present població e establiment e les dites concessions, gràcies e donacions per vós a. nós feites, sots les formes e condicions damunt dites, reverentment, com de seynor de qui molts beneficis reebuts havem, e aquelles acceptants e a elles consentents, prometem a vós los dits drets e als vostres éntegrament donar e pagar en los dits térmens e la dita vall myllorar e laurar e no pijorar, a ús e costum de bons acaptadors e lauradors, e ésser a vós e als vostress, tant com la dita vall tindrets, leals vassalls e verdaders e donarem e pagarem en los dits térmens los drets que donar devem bé e lealment, segons que desús és especificat, e farem e complirem tot ço que som tenguts fer e complir a vós e als vostres a bona fe e sens alcun engan o contrast. E per les dites coses attendre e complir, nós, dits síndichs e procuradors'e substituits, en nom nostre propri e d'aquells de qui som procuradors, obligam a vós, dit noble en Bernat de Sarrià, present e reebent, e al notari dejús scrit, axí com a pública persona stipulant e reebent en nom d'aquells a qui pertáyner pot e deu, tots los béns nostres e dels singulars de les dites aljames principals nostres, mobles e no mobles, haüts e per haver, on que sien. E per testimoni de les dites coses fem fer dues cartes' públiques per $A B C$ partides a cascuna de les parts $\left.\right|^{a}$ liuradora per lo notari dejús scrit a perdurable memòria.

Quod est actum Valencie, $1 X^{\circ}$ kalendas iulii, anno Domini $M^{\circ} \mathrm{CCC}^{\circ} X X^{\circ}$ octavo.

Sen + lyal de nós, en Bernat de Sarrià, qui les dites coses atorgam, fermam e juram. Sen ( + lyal de mi, Hamet el Balestero, sen + lyal de mi, Çaad Matrabel, procuradors damunt dits, qui les dites coses acceptam e reebem, atorgam e confermam.

Testimonis presents foren a les dites coses appellats e pregats, los honrats en Bernat d'Olius, en Pere Colom, cavallers, en Bertran de Puigmoltó, en Pelegrí Romeu, en Guillem Barrot, de casa del dit noble, en Pere de Soler, en Guillem de Coma- 
dolms, veyns d'Algiçira, en Pere Cuquetes e en Johan de lo Blancho, ciutadans de València.

Sig( Inum Antonii Jorro, notarii publici Valencie, qui hec scribi fecit et clausit, loco, die et anno prefixis, cum raso et emendato in quinta linea ubi dicitur "tractant» et cum supraposito in XVII ${ }^{a}$ linea ubi dicitur "en la dita vall" e cum raso et emendato in XXV a linea ubi dicitur "als altres fos vedat", et in XLVIII" linea ubi dicitur "tant com".

Et per procuratores predictos nobis fuit humiliter suplicatum ut omnia et singula in dicto instrumento contenta, ut superius expressata, confirmare eis de regali clemencia dignaremur, idcirco, eorum suplicacioni condescendentes benigne, volentes ut habitatores vallis predicte, presentes pariter et futuri, de bono in melius suscipiant incrementa, cum presenti carta nostra dictum instrumentum supra insertum et omnia et singula in eo contenta laudamus, aprobamus et ex certa sciencia confirmamus, mandantes universis et singulis officialibus et subditis nostris, presentibus et futuris, quod laudacionem, aprobacionem et confirmacionem nostram huiusmodi firmam habeant et observent et faciant inviolabiliter observari et contra eam sarracenos vallis predicte agravari ullo tempore non permittant. In cuius rey testimonium hanc cartam nostram inde fieri iussimus, nostri sigilli pendentis munimine roboratam.

Datum Caraynene, $11^{\circ}$ nonas augusti, anno Domini $\mathrm{M}^{\circ} \mathrm{CCC}^{\circ} \mathrm{XX} \mathrm{X}^{\circ}$ octavo.

Sig( Inum Alfonsi et cetera.

Testes sunt, reverendus Petrus, Cesaraugustanus archiepiscopus ac domini regis cancellarius, Eximinus Cornellii, dominus de Alfagerino, Petrus de Luna, Raimundus Cornelli, Gilabertus de Crudiliis.

Fuit clausum per dictum Egidium Petri, scriptorem domini regis.

Egidius Petri, mandato regio facto per Rodericum Didaci, cancellarium domini infantis Petri.

a. vida, interlineat; $b$. gran, interlineat sobre revencia, ratllat; $c$. Sequeix síndich, repetit; d. Segueix ab Caad, repetit; e. Segueix com a procuradors, repetit; $f$. Matrabell, al ms., amb la darrera / ratllada; $g$. per, interlineat; $h$. Hem desenvolupat en catala l'abreviatura llạtina sol. aquíi a latesta del document; $i$. alfarda al ms. per error, més endavant és citat correctament l'alfatra; $k$. tengús al $m s$; 1 . Segueix dites, ratllat; $m$. servhii corregit sobre servey; $n$. Segueix per, ratllat; o. hi, interlineat p. o a qui nós, interlineat; $q$. el, al $\mathrm{ms} ; \mathrm{r}$. si de la nostra gràcia o mercè ... alcuna manera, interlineat; s. Segueix a bona fe e sens alcún fe e sens alcún engan o contrast. E per les dites coses attendre e complir nós dits slndichs e procuradors e substituits, en nom nostre propri e d'aquells de qui som procuradors, ratllat; $t$. Segueix e procuradors, repetit; $u$. Segueix Matheu, ratllat 